\title{
REVENUE RISK EVALUATION FOR PPP ROAD INFRASTRUCTURE
}

\author{
Sukmo Ku ${ }^{1}$, Hong Ki An ${ }^{1}$ \\ ${ }^{1}$ Department of Public Finance and Social Policy, Korea Development Institute, Sejon-si, Korea \\ ${ }^{2}$ Faculty of Transportation Engineering, Huaiyin Institute of Technology, Huaian, China \\ Received 29 December 2019; accepted 18 March 2020
}

\begin{abstract}
Less traffic than expected and low toll revenue from the construction of transportation on infrastructure such as roads and railways are causing business failure. However, it is a reality that the responsibility of this failure is only due to the prediction accuracy of the model analyzing the demand. This is because traffic risk is always present in Public-Private Partnership (PPP) projects and government, concessionaire, and financial investors need to be managed in terms of risk such as reducing the traffic risk through clear forecasting techniques and appropriate project structure selection. In this study, we investigated what traffic risk is, and quantified the risks by measuring the traffic risks and the case analysis with a road PPP project. As a result, the traffic risk of road PPP project was estimated to be $19.3 \%$ on the average demand reduction risk compared to predicted traffic volume. In case analysis, it was analyzed as high revenue risk project because of $86.38 \%$ risk that refund given to the government by the private sector could be lower than Korean Won (KRW) 62.4 billion (USD 55.5 million), and $88.67 \%$ risk that operating period subsidy could be generated. This analysis is meaningful in that it quantifies traffic risk that we know intuitively or qualitatively. Thus, it is expected that the risk analysis based on a clear understanding of the nature of future traffic risks will be the basis of successful PPP projects.
\end{abstract}

Keywords: traffic risk, revenue risk, PPP, Monte-Carlo simulation, risk management.

\section{Introduction}

In road and railway construction projects, lower traffic than expected or lower toll revenue can be the cause of project failure. These lower traffic forecasts could also create many serious problems in projects with respect to the private sector. According to the (KTI, 2017), the minimum revenue guarantee of private investment business for expressway projects is KRW 350 billion ( $\$ 311$ million) annually. Recently over estimated future demand Uijeongbu light rail project has become a social issue in Korea. However, investment decision makers or policy makers who judge the project implementation tend to hold its responsible to only traffic modelers.

Although some projects have failed due to the overestimated future traffic, the demand for transportation projects by the private sector has been increasing due to lack of project budget. Thus, in order for projects to succeed, how to manage the future traffic is an essential step. Research related to the management of traffic has

${ }^{1}$ Corresponding author: nereid97@naver.com 
so far focused on determining the cause of the error in traffic forecasting (Flyvbjerg et al., 2005; Bain and Polakovic, 2005; Bain, 2009). However, there has been no significant research on how overestimated traffic can affect project results. Normally, traffic forecasting includes uncertainty about the future, and general sensitivity analysis and scenario analysis cannot make up for the uncertainty perfectly. Traffic risk can be affected by error, uncertainty, bias and other factors. A constant level of risk always exists so that stricter management by government, the private sector and investors is necessary to reduce the risk.

This study, therefore, has attempted to define the concept of traffic risk based on a review of previous studies. Moreover, risk factors have been defined for risk measurement methods and traffic risk has been studied.

Future traffic risk based on the survey, and precise statistical analysis also has been carried out using Oracle Crystal Ball software. In addition, this study has performed a case study on estimated future traffic with financial model of from the private sector. For purposes of an empirical analysis, Build Transfer Operate - adjusted (BTO-a) type was applied and the effects of traffic risk on the government and the private sector were identified.

\section{Understanding of Traffic, Revenue Risk and Measurement Method}

\subsection{Understanding of Traffic and Revenue Risk}

Risk can be used in various areas and it could be used as a possibility that traffic demand is lower than forecast and for inaccuracy in predicting traffic demand (Bull et al., 2017). Although new methods have been improved in forecasting traffic demand methods, traffic risk still occurs in PPP projects due to the use of uncertain parameters including travel patterns and behavior. Moreover, there is a gap between the forecasted traffic and actual traffic because the process of the future traffic demand prediction is stochastic results rather than conclusive outputs.

Bull et al. (2017) reported that the reasons for inaccuracy in the forecasting process of traffic demand are error, uncertainty and bias. The "Errors" occur either in the way of traffic prediction itself or in the process of forecasting. The "Uncertainty" refers to inaccuracies that deviate from control of the traffic forecast process. This uncertainty might be affected by the rate of economic growth, housing development planning and road construction projects during the projects and it is very difficult to grasp in the process. The "bias" is a tendency to be optimistic about future situations in order to achieve specific business goals. 


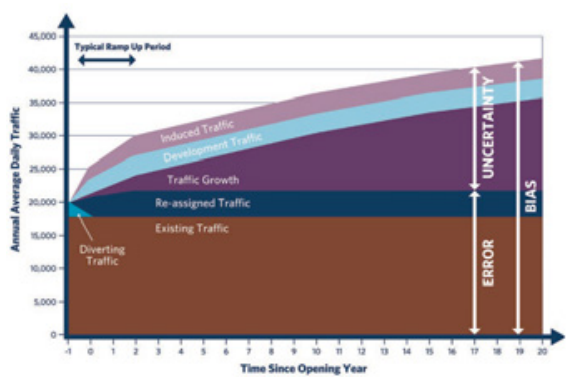

Fig. 1.

The Building Blocks of Traffic Risk

Source: (Bull et al., 2017)

Normally, the errors and uncertainty could lead to future demand gap between forecasting and actual traffic, and the bias could influence the errors and uncertainty. The uncertainty tends to increase over time and it can lead to the failure of the project as depicted in Fig. 1.

Traffic forecasting is subjective and requires assumptions about the future. These assumptions result in predictive errors, and governments, private sector operators and financial investors should conduct periodic reviews to reduce the tendency for excessively optimistic or overly conservative traffic forecasts.

\subsection{Traffic Risk Measurement Studies}

It seems that traffic risk analysis has developed with two aspects namely construction engineering which deals with risk in construction and financial engineering which deals with financial risk (Lee et al., 2002). With respect to previous studies in construction engineering, a survey with six items and 33 questions that can affect risk in private sector investment was conducted by Song et al. (1999) which tried to measure the influence of a risk factor. However, this research only focused on the comparison

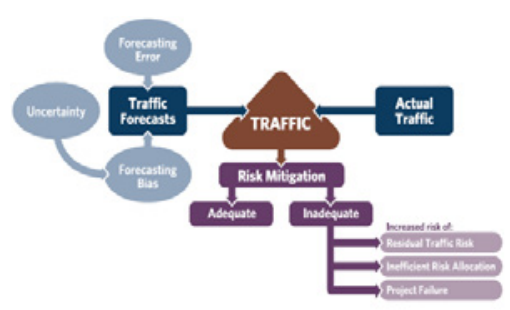

between risk factors, thus the risk was not quantified. The other study by Jung et al. (2011) assumed a probability distribution for project costs, operating expenses and operating income to analyze the financial risks of private sector investment. However, he only derived very simple assumptions and results. In construction engineering, studies related on the risk concentrated to the cost of construction or operation, thus there has been minimal research on revenue risk in such road and railway user charge projects.

On the other hand, in respect of financial engineering, research with financial option applying minimum revenue guarantee is normally conducted. This method assumes that traffic volume which is an uncertainty variable is the underlying factor in determining the option price. Moreover, the rights that the private sector is able to acquire using the minimum income guarantee can be calculated using the Monte-Carlo model (Cheah and Liu 2006; Huang and Chou, 2006; Jun, 2008; Aldrete et al., 2012; Chang and Lee, 2012; Ku et al., 2017).

In terms of financial engineering, the main focus is to measure the volatility of financial assets, thus this study attempts to measure the traffic risk from a construction 
engineering aspect. In order to evaluate the traffic risk, two methods (i.e. probability standard and impact standard) are popular because a significance of risk can be described as expectation with the standards (Aleshin, 2001; Walewski and Gibson, 2003). However, risk factors are sometimes measured in a hierarchy by weighting them by their relative importance because it is not easy for experts to assess a variety of risks at once (Kang et al., 2001). In this study, in order to measure the risk, two steps are necessary (i.e. to measure the weight for risk factors via weight analysis and calculation the risk index to assess the risk level of the entire project by combining the probability values of each risk factor). The level of risk can be calculated with relative weight and degree of risk as presented in Equation 1.

$L=W \times R$

Where $L$ is the level of risk;

$\mathrm{W}$ is relative weigh; and

$\mathrm{R}$ is degree of risk.

The degree of risk can be measured by Equation 2.

$R=P \times l$

Where $\mathrm{R}$ is the degree of risk;

$\mathrm{P}$ is probability of risk; and

$\mathrm{I}$ is risk impact.

The research on evaluation of the risk degree can be carried out with collected data from the past or using expert subjective judgment. The collected data in the past, however, sometimes cannot reflect current and future situations properly, thus the risk is variable in accordance with types of data and collection periods. Projects, therefore, are usually undertaken by the expert subjective judgment due to difficulty of traffic risk quantification.

\section{Research Methodology}

\subsection{Factor Derivation on Revenue Risk}

There have been some studies on the revenue risk reasons by Flyvbjerg et al. (2005) and Bain (2009); here, a bottom-up method was applied for the finding of revenue risk. The advantages of bottom-up method are that it is easy to identify the risk causes roughly and easy to estimate how can the causes affect the risk based on the past data. However, there is a limitation on the method to measure the risk significance. For example, in the process of four steps of demand forecasting, it is only possible to divide errors in the trip generation step, distribution step and assignment step. This means that the bottom-up method cannot define and recognize the significance of errors. This study, therefore considers the top-bottom method with two traffic risks together namely errors and uncertainty. As described in section 2 , errors relate to technical problems in the forecasting process and uncertainty for future demand forecasting like economic growth.

With respect to a toll road by private sector investment, the main output is not only traffic forecasting, but also revenue forecasting. In addition, in highway operation periods, changes of toll and price can be an important risk cause for decision making for the government and the private sector. Therefore, this study will consider the factors affecting the price as one of the risk factors as well. In addition, for feasibility analysis, traffic volume and tolls are able to influence the revenue and the rate of exemption from 
the toll is included in traffic risk in the case of a toll road. Thus, as presented in Table 1 , four risk factors namely predictive error risk, future uncertainty risk, future toll risk and discount exemption vehicle rate risk are selected in this study.

\section{Table 1}

Selection of Revenue Risk Factors in This Study

\begin{tabular}{|c|c|}
\hline Category & Description \\
\hline \multirow{2}{*}{ Traffic Risk } & Predictive error risk \\
\cline { 2 - 2 } & Future uncertainty risk \\
\hline \multirow{2}{*}{ Price Risk } & Future toll risk \\
\cline { 2 - 2 } & Discount exemption vehicle rate risk \\
\hline
\end{tabular}

\subsection{The Measurement of Revenue Risk}

It is not easy to assess traffic and price risk as a quantified figure because it depends on each project's characteristic or other external factors. Thus, measuring on the basis of subjective judgment by an expert may be easier to identify the approximate level of risk.

In this study, the revenue risk can be calculated by multiplying the risk occurrence probability with risk degree.
The two factors, risk occurrence probability and risk degree were arrived at through an expert survey. For the survey, the questionnaire is organized into two phases; phase 1 is to determine the importance of risk factors and phase 2 is to identify the degree of risk for each factor. In total 26 participants were selected randomly from private project roads under actual operation and government public institutions with extensive experience in private projects for the private sector, as shown in Table 2.

\section{Table 2}

An Expert Survey Information

\begin{tabular}{|c|c|}
\hline Survey Period & 2018. 1. 17-2018. 1.25 \\
\hline Survey Method & Web survey \\
\hline \multirow{2}{*}{ Survey Host } & $\begin{array}{c}\text { Korea Development Institute, Economic } \\
\text { Information and Education Center }\end{array}$ \\
\hline \multirow{2}{*}{ Questionnaire Survey Target } & Government: 2 \\
\cline { 2 - 2 } & Public institution: 4 \\
\cline { 2 - 2 } & Private sector: 20 \\
\cline { 2 - 2 } & Total 26 survey participants \\
\hline
\end{tabular}

The probability of risk and degree of risk are supplied with weighting related to the risk factors as shown in Table 3. At this stage, identifying the setting value is problematic because a variation in this value might change the results significantly. 
Table 3

Weight Setting for Quantifying Expert Questionnaire

\begin{tabular}{|c|c|c|c|c|}
\hline \multicolumn{2}{|c|}{ Probability of Risk } & \multicolumn{3}{|c|}{ Risk Intensity (Impact) } \\
\hline Weighting & Setting value & Weighting & $\begin{array}{c}\text { Setting Value } \\
\text { Decrease in Traffic } \\
\text { Volume }\end{array}$ & $\begin{array}{c}\text { Setting Value } \\
\text { Revenue Fluctuation }\end{array}$ \\
\hline Very Low & 0.1 & Very Little & $\begin{array}{c}\text { Minimal or } \\
\text { no Impact }\end{array}$ & $\begin{array}{c}\text { Reference Value } \\
\times-2\end{array}$ \\
\hline Low & 0.3 & Little & $<5 \%$ & $\begin{array}{c}\text { Reference Value } \\
\times-1.5\end{array}$ \\
\hline Medium & 0.5 & Moderate & $5-15 \%$ & Reference Value \\
\hline High & 0.7 & Severe & $15-22 \%$ & $\begin{array}{l}\text { Reference Value } \\
\times 1.5 \\
\end{array}$ \\
\hline Very High & 0.9 & Very Severe & $22-30 \%$ & $\begin{array}{c}\text { Reference Value } \\
\times 2\end{array}$ \\
\hline
\end{tabular}

This research applies 30 percent of risk intensity, which is the maximum error range in future demand forecasting, and a maximum of twice the revenue in the financial forecasting.

\subsubsection{Selection of Probability Distribution of Risk Factors}

The probability distribution and parameter selection of the risk factors affect the accuracy of the analysis results, so the distribution is determined through statistical analysis. Normally, maximum likelihood estimation method can be used for estimation of probability distribution and parameters (Bae and Jeon, 1999; and Lee et al., 2005), as presented in Equation 3.

$\mathrm{p}(\theta \mid y) \propto \mathrm{p}(\mathrm{y} \mid \theta) \pi(\theta)$

Where, $\mathrm{p}(\theta \mid \mathrm{y})$ is posterior distribution, $\pi(\theta)$ is prior distribution and $p(y \mid \theta)$ is likelihood function.

In addition, to verify output the AndersonDarling statistical test (AD) can be used for this research, as shown in Equations 4, 5 and 6.

$Q_{n}=n \int_{-\infty}^{+\infty}\left[F_{n}(x)-F(x)\right]^{2} \psi(x) d F(x)$

Where, $\psi(\mathrm{x})$ is weighting function and it can be expressed in Equation 3.

$\psi(x)=\left[F(x)(1-F(x)]^{-1}\right.$

$A_{n}^{2}=n \int_{-\infty}^{+\infty} \frac{\left[F_{n}(x)-F(x)\right]^{2}}{F(x) 1-F(x)} d F(x)$

\subsubsection{Correlation and Risk Results}

If the risk factors have correlation with each other, one factor affects the final output. This research assumes that the selected four factors including predictive error risk, future uncertainty risk, future toll risk, and discount exemption vehicle rate risk have no correlation. In fact, there is an inverse relationship between traffic volume and cost; however, future cost in this research involves the increase and decrease in both. Moreover, traffic volume means that future traffic forecasting (not traffic increase and decrease itself), so that risk factors can be regarded as having a mutually exclusive relationship. 
Table 4

Measures of Risk Level

\begin{tabular}{|c|c|c|c|c|}
\hline \multirow{2}{*}{ Division } & \multicolumn{2}{|c|}{ Traffic Risk } & \multicolumn{2}{c|}{ Revenue Risk } \\
\cline { 2 - 5 } & Error Risk & Uncertainty Risk & Price Risk & $\begin{array}{c}\text { Discount } \\
\text { Exemption Risk }\end{array}$ \\
\hline Mean & $7.0 \%$ & $12.3 \%$ & $2.0 \%$ & $4.0 \%$ \\
\hline Max & $11.7 \%$ & $21.6 \%$ & $4.4 \%$ & $8.6 \%$ \\
\hline Min & $2.5 \%$ & $5.1 \%$ & $0.3 \%$ & $0.0 \%$ \\
\hline Skeness & 0.10 & 0.47 & 0.66 & 0.32 \\
\hline Kutosis & -0.75 & 0.54 & 0.97 & 0.31 \\
\hline Std. Dev & 0.03 & 0.04 & 0.01 & 0.02 \\
\hline Fit & Beta & Logistics & Log regular & Log regular \\
\hline
\end{tabular}

In order to decide the optimum distribution chart, Oracle Crystal Ball software was used in this research. Table 4 and Fig. 2 . present the risk intensity and suitable probability distribution. Beta distribution is good for analysis of error risk and logistics distribution is suitable for uncertainty risk. Furthermore, log regular distribution is suitable for the analysis of price risk and discount exemption risk.

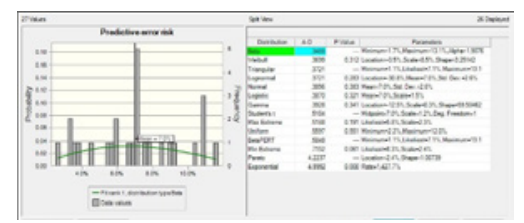

Predictive Error Risk

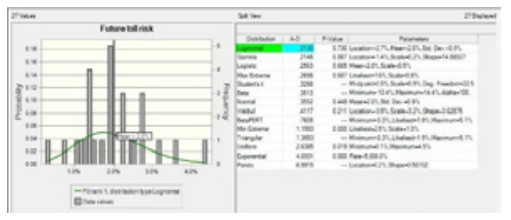

Future Toll Risk

Fig. 2.

Probability Distribution According to Risk Factors

\section{The Application of Traffic Risk}

As mentioned earlier, this research attempts to measure the financial risk in the private sector in accordance with traffic risk that
Error risk and uncertainty risk in traffic risk were around 7.0 percent and 12.3 percent respectively. This means that risk in demand compared to the forecasting traffic volume was 19.3 percent on average. Revenue risk refers to the degree of variation based on the average value and can be measured by standard deviation. The price risk (2.0 percent) and discount exemption risk (4.0 percent) in revenue risk were measured.

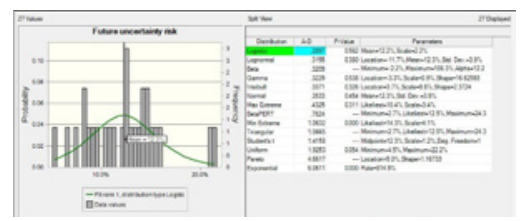

Future Uncertainty Risk

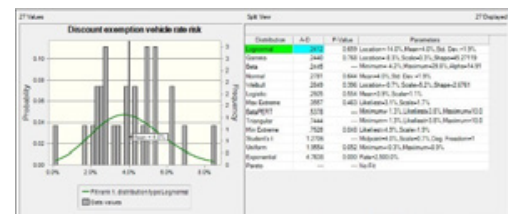

Discount Exemption Vehicle Rate Risk

is combination between collected traffic volume and financial modeling. In order to measure the financial risk properly, MonteCarlo Simulation was used, which generated random numbers and then analyzed the risk 
with probability distribution. This method is different from simple sensitivity analysis or scenario analysis due to producing results with multiple probability variables at the same time.

\subsection{Project Outline and Main Assumptions}

This research selected the one of PPP projects, which is a $\mathrm{BTO}-\mathrm{a}$ project (OO highway project), to measure the traffic risk (the PPP project name was marked as "OO" because the proposal was nondisclosure until the project was decided). Generally, BTO-a sets the annual investment risk, and if an operating revenue is less than the investment risk the government provides financial support. If an operating revenue exceeds the redemption amount the government can claw back a certain amount. Therefore, it can be seen that the investment risk and redemption amount vary in accordance with actual traffic volume. However, current PPP projects tend to carry forward a business model with only forecast future traffic volume and do not consider the uncertainty arising from future traffic volume. Thus, in terms of the government and the private sector, the risk analysis of traffic is an essential step to reduce the unnecessary expenditure.

Table 5 presents the BTO-a project overview. The project was proposed with 300 billion Won (USD 266.9 million) by private investment and the estimated operation cost and revenue are 193 billion Won (USD 171.6 million) and 833 billion Won (USD 740.4 million) respectively. In order to calculate the investment risk, the five-year treasury bond rate (1.52 percent) and the additional interest ( 1.5 percent) were applied. In addition, 70 percent and 30 percent of the government risk sharing rate and redemption rate were assumed. On the basis of the assumptions, the final estimate of return rate for the private sector was premised as 2.5 percent.

\section{Table 5}

Case Study Project Overview

\begin{tabular}{|c|c|c|c|}
\hline Category & Description & Category & Description \\
\hline Title & OO - XX highway & Inflation rate & $2 \%$ \\
\hline Construction Period & $\begin{array}{c}5 \text { years } \\
(2017-2022)\end{array}$ & $\begin{array}{c}\text { Government's } \\
\text { Risk-sharing }\end{array}$ & $70 \%$ \\
\hline $\begin{array}{c}\text { Operation Period } \\
\text { Total Private } \\
\text { Investment (Current) }\end{array}$ & USD 266.9 million & $\begin{array}{c}\text { Project's Rate of } \\
\text { Return }\end{array}$ & $30 \%$ \\
\hline $\begin{array}{c}\text { Total Operation Cost } \\
\text { Total Operation } \\
\text { Revenue }\end{array}$ & $\begin{array}{c}\text { USD 171.6 million } \\
\text { (for 30 years) }\end{array}$ & $\begin{array}{c}\text { USD 740.4 million } \\
\text { (for 30 years) }\end{array}$ & Subsidy \\
\hline
\end{tabular}

Note: USD 1 = 1,124 KRW in January 2019

\subsection{Analysis of Results}

As mentioned earlier, this research tries to measure the traffic risk with four probability variables of traffic risk and revenue risk using Crystal Ball software. In order for precise output, 3000 iterations of Monte-Carlo simulations were performed.

As depicted in Fig. 3, total estimated revenue is 833 billion Won (USD 740.4 million) for 30 
years and this is 77.47 percent of continuous density function. It means that there is $\mathbf{7 7 . 4 7}$ percent probability that revenue will be less than the reference value 833 billion Won
(USD 740.4 million). The 77.47 percent of probability can indicate that the government and private sector both would have risk to continue the project.

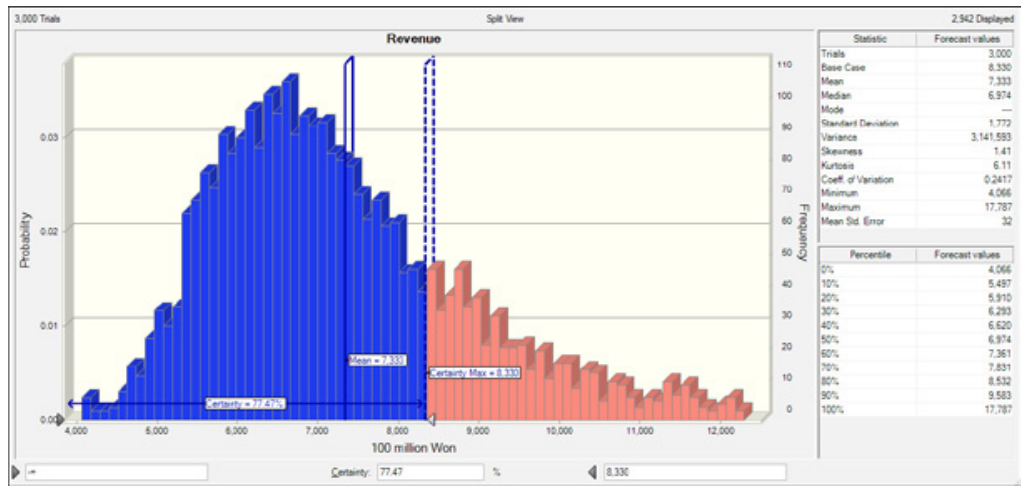

Fig. 3.

Simulation Results of Revenue

The other analysis, namely subsidy and redemption in respect of the government were also performed by the Crystal Ball simulation. As described in Table 6, the case project had that redemption was 62.4 billion won (USD 55.5 million), subsidy was zero and the rate of return (IRR) was 2.45 percent. However, the results of applying revenue risks showed that on average, 32.1 billion won (USD 28.6 million) in redemption, 3.6 billion won (USD 3.2 million) in subsidy and 1.41 percent in rate of return were worse than forecast.

\section{Table 6}

Summary Statistics

\begin{tabular}{|c|c|c|c|}
\hline & Redemption & Subsidy & IRR \\
\hline Base Case & $\begin{array}{c}\text { 62.4 billion won } \\
\text { (USD 55.5 million) }\end{array}$ & $0.45 \%$ \\
\hline Mean & $\begin{array}{c}32.1 \text { billion won } \\
\text { (USD 28.6 million) }\end{array}$ & $\begin{array}{c}\text { 3.6 billion won } \\
\text { (USD 3.2 million) }\end{array}$ & $1.41 \%$ \\
\hline Median & $\begin{array}{c}24.8 \text { billion won } \\
\text { (USD 22.1 million) }\end{array}$ & $\begin{array}{c}6.0 \text { billion won } \\
\text { (USD 5.3 million) }\end{array}$ & $1.44 \%$ \\
\hline Std. Dev & $\begin{array}{c}31.1 \text { billion won } \\
\text { (USD 27.7 million) }\end{array}$ & $\begin{array}{c}4.7 \text { billion won } \\
\text { (USD 4.2 million) }\end{array}$ & $0.45 \%$ \\
\hline Variance & 96.995 & 2.208 & $0.00 \%$ \\
\hline Skewness & 1.69 & 2.68 & -0.5543 \\
\hline Kurtosis & 7.12 & 15.43 & 3.62 \\
\hline Coeff. Of Var & 0.9705 & 0 & 0.3207 \\
\hline Minimum & 0 & 478 & $-0.53 \%$ \\
\hline Maximum & 2.338 & 1 & $2.86 \%$ \\
\hline Mean Std. Error & 6 & $0.01 \%$ \\
\hline
\end{tabular}

Note: USD 1=1,124 KRW in January 2019 
As can be seen in Fig. 4, the restitution is 62.4 billion Won (USD 55.5 million) and the probability that the redemption amount is less than 62.4 billion won (USD 55.5 million) is 86.38 percent and the subsidy is less than zero won (USD 0) is 11.33 percent.

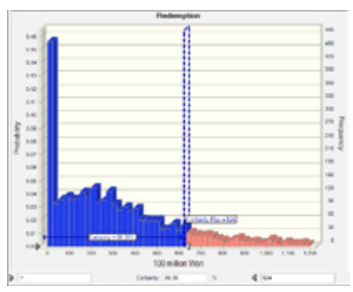

(a) Redemption amount

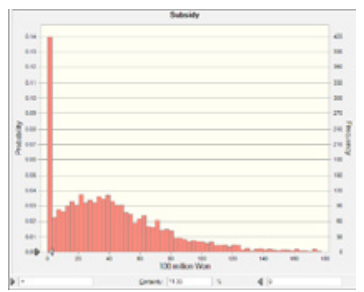

(b) Subsidy

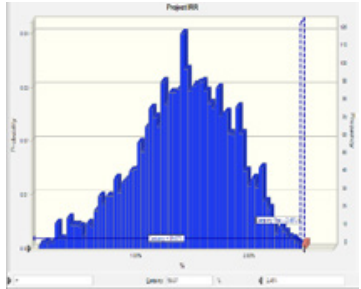

(c) Project IRR

Fig. 4.

Histogram of Simulation Results

This means that the risk of a reduction in the predicted redemption amount is 86.38 percent and the risk of a subsidy occurring is 88.67 percent. Meanwhile, the private sector also has a 99.87 percent probability of their rate of return falling below project 2.45 percent.

\section{Conclusion and Implication}

\subsection{Conclusion}

This study considered traffic risk with the focus on a road PPP (BTO-a) project, identified traffic risk factors, and measured risk degree for each risk factor. Further, the analysis was conducted focusing on real cases for utilization of measured traffic risk.

According to this study, the traffic risk was analyzed to be an average of 19.3 percent of the risk of reduced demand compared to predicted traffic. In addition, Crystal Ball simulation was performed for measuring the risk level based on a financial model applying traffic risk and revenue risk. The risk is 86.38 percent, which is less than the 62.4 billion Won (USD 55.5 million) that the private sector offered to the government. Although a subsidy was not originally scheduled, a 88.67 percent of subsidy was likely to occur during the operation period. This means that the PPP project was a highly risky project for the government. Also, there is a 99.87 percent risk of the earnings rate in the private sector falling below 2.45 percent. This study is meaningful in that it is quantified and numerically presented the traffic risk that was previously only represented as intuitively or qualitatively.

\subsection{Implications}

In respect of some PPP projects, the importance of traffic risk has been further increased by over-estimated traffic leading to continued financial turmoil, bankruptcy or renegotiation. Thus, BTO-a has recently taken center stage mainly due to its merits of managing the traffic risk for both the government and the private sector.

Although this BTO-a needs to proceed with an understanding of traffic risk, the government and private sector seem to lack an understanding of the nature 
of transportation and revenue risk, and of demand forecasting skills. Thus, the accuracy of a model that is the difference between the actual traffic volume and the forecasted traffic volume on the project in progress is not the only issue. Traffic risk always accompanies any road projects; however, it can be reduced and the remaining risks can be effectively managed.

Since the results of this study include subjective factors, such as measuring the inherent risks of the project itself or depending on the entity pushing forward with the private project, it is unreasonable to establish a uniform framework for analysis for all projects. However, attempts at risk analysis based on a clear understanding of the nature of traffic risk will be the basis for successful private investment projects.

\section{References}

Aldrete, R.; Bujanda, A.; Valdez, G. 2012. Valuing public-sector revenue risk exposure in transportation public-private partnerships, Transportation Research Record: Journal of the Transportation Research Board 2297: 88-96.

Aleshin, A. 2001. Risk management of international projects in Russia, International Journal of Project Management 19(4): 207-222.

Bae, DS, Jeon, YL. 1999. Reliability Analysis, Arche.

Bain, R. 2009. Error and optimism bias in toll road traffic forecasts, Transportation 36(5): 469-482.

Bain, R.; Polakovic, L. 2005. Traffic Forecasting Risk Study 2005: Through Ramp-Up and Beyond, Standard \& Poors, London. Available from Internet: <http:// www.robbain.com/Traffic\%20Forecasting\%20Risk\%20 2005.pdf $>$.
Bull, M.; Mauchan, A.; Wilson, L. 2017. Toll-road PPPs Identifying, Mitigating and Managing Traffic Risk. The Public - Private Infrastructure Advisory Facility (PPIAF).

Chang, Y.; Lee, C. 2012. A Study on the Risk Assessment of Real Estate Investment: Using Monte Carlo Simulation, The Korea Spatial Planning Review 72: 79-102.

Cheah, C.Y.; Liu, J. 2006. Valuing governmental support in infrastructure projects as real options using Monte Carlo simulation, Construction Management and Economics 24(5): 545-554.

Flyvbjerg, B.; Holm, M.; Buhl, S. 2005. How (in) accurate are demand forecasts in public works projects?, Journal of the American Planning Association 71(2): 131-146.

Huang, Y. L.; Chou, S. P. 2006. Valuation of the minimum revenue guarantee and the option to abandon in BOT infrastructure projects, Construction Management and Economics 24(4): 379-389.

Jun, J. B. 2008. Valuation of governmental guarantee in $B O T$ project finance with real option analysis. Texas A\&M University.

Jung, D.; Kim, H.; Hyun, C.; Kim I. 2011. A Study on the Financial Risk Assessment of SOC Private Investment Projects: focused on Light Rail Transit Projects, Korean Journal of Architectural Engineering 17(5): 109-116.

Kang, I.; Kim, C.; Son, C.; Park, H. 2001. A Case Study on Risk Analysis of Large Construction Projects, Korean Journal of Construction Engineering and Management 2(2): 98-108.

KTI. 2017. A study on Reforming Supervision System of PPP Toll Road for Public Interest. The Korea Transport Institute, Korea.

Ku, S.; Lee, S.; Lee, S. 2017. Real Option Analysis to Value Government Risk Share Liability in BTO-a Projects, Journal of Korean Society of Transportation 35(4): 360-373. 
Lee, G.; Lee M.; Lee, Y.; Kim, N.; Park, G. 2002. Risk Management of Contingent Liability from Government Guarantee in PPI Project. Korea Research Institute for Human Settlements (KRIHS).

Lee, Y.; Nam, D.; Lim, K. 2005. Development of Evaluation Model for ITS Project using the Probabilistic Risk Analysis, Journal of Korean Society of Transportation 23(3): 95-108.
Song, B.; Son, C.; Kim, Y. 1999. Efficient Risk Sharing Methods for Private Sector Developers Investing in SOC, Journal of the Architectural Institute of Korea 15(6): 113-120.

Walewski, J.; Gibson, G. 2003. International project risk assessment: Methods, procedures, and Critical Factors. Center for Construction Industry Studies, University of Texas at Austin, Report 31. 